\title{
PROCESSO CICATRICIAL DE SUTURA EM CECO COM OS FIOS POLIPROPILENE, POLIGLECAPRONE 25 E GLICOMER 60 EM RATOS
}

\author{
Healing process with polipropilene, poliglecaprone 25 and glicomer 60 in cecorra- \\ phy in rats
}

\author{
Luiz Masakatso NOMURA, Jurandir Marcondes RIBAS-FILHO, Osvaldo MALAFAIA, \\ Ulrich Andreas DIETZ, Thelma Laroka SKARE, Marcio Hiroaki KUME
}

ABCDDV/647

Nomura LM, Ribas-Filho JM, Malafaia O, Dietz UA, Skare TL, Kume MH. Processo cicatricial de sutura em ceco com os fios polipropilene, poliglecaprone 25 e glicomer 60 em ratos. ABCD Arq Bras Cir Dig 2009;22(2):82-8

RESUMO - Racional - A despeito de grandes avanços na elucidação dos fatores locais e gerais que interferem na cicatrização, o estado atual ainda não permite dispensar o uso do fio de sutura em intervenções cirúrgicas e a busca pelo fio ideal ainda continua. Objetivo - Avaliar suturas em ceco de ratos realizadas com fio monofilamentar absorvível de glicomer $60\left(\right.$ Monosyn $\left.^{\circledR}\right)$, em relação aos fios polipropilene (Prolene $\left.{ }^{\circledR}\right)$ e poliglecaprone 25 $\left(\right.$ Monocryl $^{\mathbb{}}$ ). Método - Foram utilizados 72 ratos Wistar, divididos em três grupos de 24 denominados grupo polipropilene, poliglecaprone e glicomer. Os animais de cada grupo foram distribuídos em três subgrupos de oito e avaliados no $3^{\circ}, 7^{\circ}$ e $14^{\circ}$ dias de pós-operatório. Os parâmetros estudados foram: teste de resistência à insuflação de ar atmosférico; aspectos macroscópicos; as características histológicas e taxa de hidroxiprolina tecidual. Resultados - $\mathrm{O}$ teste de resistência à insuflação de ar atmosférico apresentou baixos valores no $3^{\circ}$ dia, com elevação no $7^{\circ}$, mantendo-se nos mesmos níveis no $14^{\circ}$ dia, sendo semelhantes em todos os fios estudados. Na análise estatística, não se observou diferença significativa entre os grupos no $3^{\circ}$, $7^{\circ}$ e $14^{\circ}$ dias de pós-operatório, porém houve aumento significativo da pressão auferida, comparando-se os dias 3 e 7 , em todos os grupos. Na análise histológica, avaliada quanto aos aspectos de reação inflamatória, proliferação fibroblástica, colagenização, coaptação das bordas e reepitelização, houve no $7^{\circ}$ dia significativamente mais animais do grupo polipropilene com colagenização moderada em relação aos grupos poliglecaprone e glicomer. Os demais resultados não diferiram entre os fios estudados. Na determinação da taxa de hidroxiprolina tecidual, obteve-se a menor taxa nos subgrupos de $3^{\circ}$ dia de pós-operatório, de todos os três grupos estudados, observando-se assim paralelismo com o ganho de resistência tênsil à insuflação de ar. Conclusão - O fio de Monosyn ${ }^{\circledR}$ equiparou-se, nos parâmetros estudados, aos fios de Prolene ${ }^{\circledR}$ e Monocryl ${ }^{\circledR}$ na realização de sutura em ceco de ratos. DESCRITORES - Fio de sutura. Cicatrização. Cirurgia

\section{INTRODUÇÃO}

Desde os tempos mais remotos, os materiais de sutura foram motivos de grandes preocupações para os cirurgiões. Assim, nos primórdios da cirurgia, os fios eram confeccionados domesticamente para serem utilizados em operações. A despeito de grandes avanços na elucidação dos fatores locais e gerais que interferem na cicatrização, o estado atual ainda não permite dispensar o uso do fio de sutura em muitas intervenções cirúrgicas para manter as bordas da ferida coaptada.

Até a década de quarenta do século passado, os fios disponíveis eram feitos de produtos naturais, tais como seda, algodão, linho e categute ${ }^{13}$. Apesar de serem muito utilizados, estes materiais apresentam o inconveniente de provocar reação tecidual intensa. Com o advento de fibras sintéticas, surgiram novos materiais, inicialmente os inabsorvíveis como polipropilene, fio monofilamentar, que mantém resistência tênsil por tempo prolongado e útil na presença de infecção. É considerado biologicamente inerte por provocar

Trabalho realizado no Programa de Pós-Graduação em Princípios da Cirurgia da Faculdade Evangélica do Paraná/Hospital Universitário Evangélico de Curitiba, Curitiba, PR, Brasil

Endereço para correspondência: Luiz Masakatso Nomura, e-mail: ipem@evangelico.org.br pouca reação tecidual ${ }^{17}$. Por essas características, é fio de sutura amplamente utilizado, principalmente em operações de grande porte e de risco grande. Posteriormente foram lançados os absorvíveis e multifilamentares, dentre eles o ácido poliglicólico e a poligalactina 910 que, ao contrário do categute, apresentam as características de provocarem menor reação inflamatória e resistência tênsil maior. Em seguida apareceram os absorvíveis monofilamentares, o polidioxanone e poligliconato, com o mesmo desempenho dos multifilamentares, porém necessitavam de tempo médio ou longo para sua absorção. Na última década foi produzido o poliglecaprone 25 , fio monofilamentar e absorvível. Apresenta como característica a boa manuseabilidade, tempo de absorção previsível, resistência tênsil inicial alta e provoca pouca reação tecidual ${ }^{3,16}$.

Como se observa na evolução histórica, novos produtos - fruto da procura pelo fio ideal -, são colocados à disposição do cirurgião. Alguns foram abandonados, devido aos maus resultados obtidos em experimentos ou na prática clínica. Outros ganharam a confiança do cirurgião e são passados às novas gerações. Contudo ainda não se encontrou o fio cirúrgico totalmente inócuo.

O presente estudo tem como objetivo avaliar, comparativamente, a evolução da cicatrização de sutura em ceco de ratos com o fio monofilamentar absorvível Monosyn ${ }^{\circledR}$, 
em relação aos fios de Prolene ${ }^{\circledR}$ e Monocryl ${ }^{\circledR}$, mediante determinação de resistência à insuflação de ar atmosférico, análise dos aspectos macroscópicos da mucosa, avaliação histológica e dosagem da taxa de hidroxiprolina tecidual.

\section{MÉTODO}

Este trabalho foi realizado no Instituto de Pesquisas Médicas do Programa de Pós-Graduação em Princípios da Cirurgia da Faculdade Evangélica do Paraná/Hospital Universitário Evangélico de Curitiba, Curitiba, PR, Brasil.

Foram utilizados 72 ratos Wistar, machos, adultos, com peso corpóreo variando entre 160 e $200 \mathrm{~g}$. Foram divididos em três grupos de 24 , sendo o primeiro considerado grupo controle e denominado grupo polipropilene; o segundo foi denominado grupo poliglecaprone e o terceiro, grupo glicomer. Todos os animais submeteram-se ao mesmo procedimento cirúrgico que foi cecotomia parcial e sutura em plano total. Os animais de cada grupo foram separados em subgrupos de oito animais, para os períodos de avaliação de 3, 7 e 14 dias de pós-operatório. Receberam ração própria para a espécie $\left(\mathrm{Nuvilab}^{\circledR} \mathrm{CR}\right.$, Nuvital) e tiveram livre acesso à água. Doze horas antes do ato operatório foi retirada a ração dos animais, permanecendo livre $\mathrm{o}$ acesso à água. Todos tiveram anestesia inalatória colocado sob uma campânula de vidro, onde previamente havia sido introduzido chumaço de algodão embebido em éter sulfúrico. Era considerado anestesiado o momento quando o animal se apresentava inconsciente, cessava os movimentos voluntários e não tinha reação ao manuseio cirúrgico.

\section{Técnica operatória}

Todos se submeteram a procedimento padrão de antissepsia e tricotomia, e não se utilizou preparo de cólon ou administração de antibióticos. Procedeu-se sorteio para determinar qual fio de sutura seria utilizado em cada animal.

O procedimento cirúrgico constou das seguintes etapas principais:

a) Laparotomia mediana, com aproximadamente $5 \mathrm{~cm}$ de extensão para acesso à cavidade peritoneal;

b) Identificação do ceco e realização de secção transversal parcial de aproximadamente $2 \mathrm{~cm}$ (Figura 1).

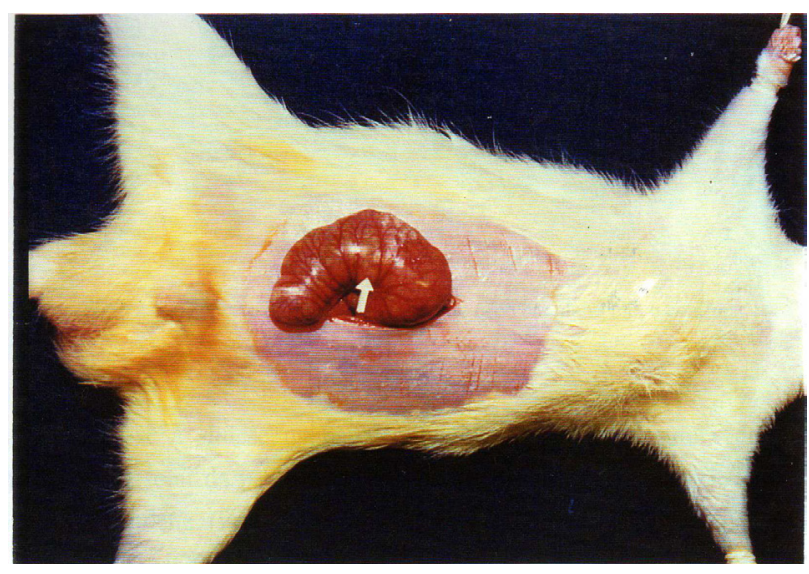

FIGURA 1 - Ceco exposto com identificação da área a ser seccionada. c) Sutura da incisão de forma contínua, em plano único total, com o fio de polipropilene (Propilene ${ }^{\circledR}$ ), na espessura 4-0 USP com agulha cilíndrica de 1,5 cm (TMC-15 CIRUMÉDICA), com o fio poliglecaprone 25 (Monocryl $^{\circledR}$ ), na espessura de 4-0 USP com agulha cilíndrica de $1,5 \mathrm{~cm}$ (TAPER RB-1 Ethicon) e com fio de glicomer 60 (Mono$\left.\operatorname{syn}^{\circledR}\right)$, na espessura de 4-0 USP com agulha cilíndrica de $1,5 \mathrm{~cm}$ (HR22, B. Braun Surgical, Alemanha), conforme os respectivos grupos. Procurou-se proceder às suturas de maneira a realizar justaposição das bordas viscerais da parede cecal, transfixando-se a sua parede a cerca de $2 \mathrm{~mm}$ de cada nó (Figura 2). A revisão da cavidade e a anastomose foi analisada antes da síntese da parede abdominal.

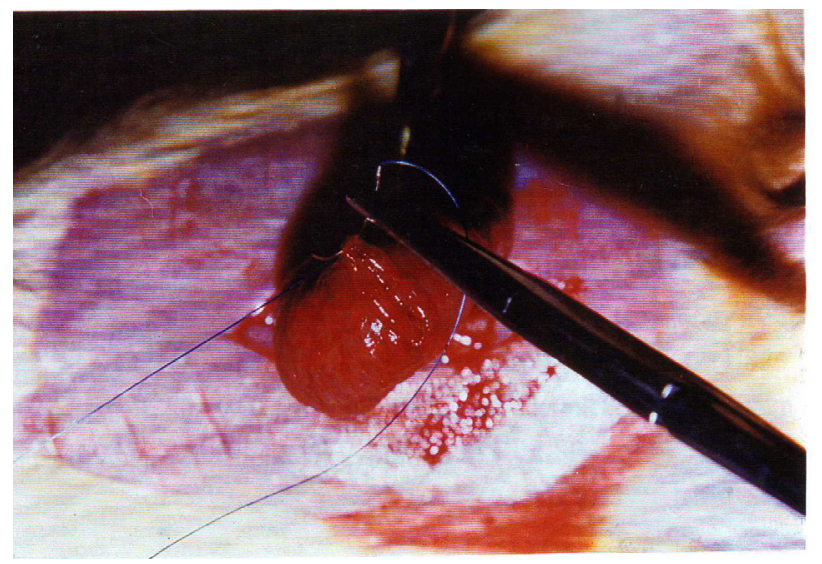

FIGURA 2 - Aspecto da sutura contínua da incisão do ceco em plano único

d) síntese da parede abdominal e pele da forma habitual, igualmente ralizada em todos os animais.

Após a operação, os animais foram acondicionados em gaiolas individuais para acompanhamento até recuperação da anestesia. Em seguida foram acondicionados em gaiolas com quatro ratos cada, sendo identificadas conforme o grupo, subgrupo e o período de avaliação. Receberam livre acesso à água e ração seis horas após o procedimento cirúrgico. Foram examinados duas vezes ao dia, observando-se disposição para alimentação, atividade motora e complicações da ferida operatória.

A eutanásia foi realizada colocando-se cada animal sob campânula de vidro contendo éter sulfúrico até que ocorresse o óbito.

\section{Avaliação macroscópica}

Avaliaram-se os aspectos de parede abdominal, cavidade abdominal, superfície externa e interna e resposta ao teste de resistência à insuflação de ar atmosférico.

\section{Da parede, cavidade abdominal e da peça cirúrgica}

Iniciou-se com a inspeção da cicatriz abdominal, para ver a presença ou não de coleção líquida no tecido celular subcutâneo, infecção e a integridade das suturas. Realizou- 
se, em seguida, a abertura da cavidade abdominal mediante duas incisões transversais (uma abaixo do xifóide e outra acima do púbis) e outra lateralmente à cicatriz mediana decorrente do ato operatório prévio para se ter acesso à cavidade abdominal longe da incisão mediana.

$\mathrm{Na}$ cavidade peritoneal buscaram-se sinais sugestivos de infecção ou a formação de abscesso ou plastrão, aderências, presença eventual de fístula no nível da anastomose e a sua integridade.

Após tais observações, procedeu-se à retirada da peça cirúrgica, incluindo ceco, cólon ascendente e um segmento de íleo de aproximadamente $4 \mathrm{~cm}$. As estruturas ou órgãos que estavam aderidos à anastomose do ceco eram retirados em monobloco. A peça cirúrgica foi lavada em água corrente e colocada em posição anatômica sobre superfície rígida. Em seguida observou-se o aspecto da anastomose pela sua vista externa, a presença de aderências, infecção, deiscência ou fístula. Todas as estruturas aderidas à anastomose eram mantidas intactas.

\section{Teste de resistência à insuflação de ar atmosférico}

Foi realizado segundo a metodologia proposta por Warde $^{20}$, obedecendo às seguintes etapas: a) preparo da peça cirúrgica, mantendo-se as estruturas aderidas a ela; b) oclusão do íleo terminal mediante ligadura com fio de algodão 2-0 USP e introdução de uma sonda siliconizada de calibre $\mathrm{n}^{\circ} 6$ na porção proximal do cólon ascendente com ligadura dele sobre a sonda usando fio de algodão 2-0 USP; conexão à bomba de infusão para insuflação de ar em forma contínua e constante, e a manômetro eletrônico para medir a pressão do ar insuflado em milímetros de mercúrio; c) submersão da peça em um recipiente de vidro com água; d) insuflação gradativa de ar, até a ocorrência de borbulhamento na água, evidenciando a ruptura da peça. Anotou-se o local da ruptura e a pressão em milímetros de mercúrio, auferida no momento da ruptura (Figuras $3 \mathrm{a}$ e $3 \mathrm{~b}$ ).
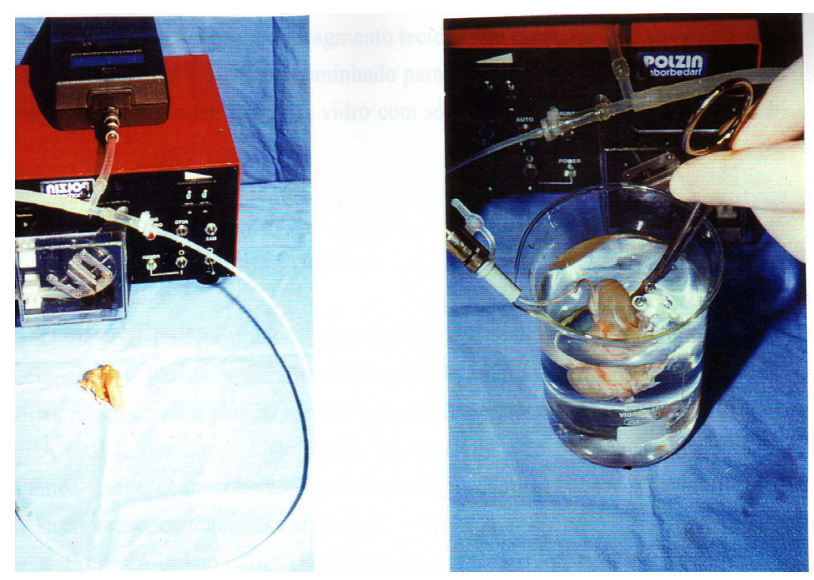

FIGURA 3 - a) Bomba de insuflação contínua de ar conectada a manômetro eletrônico; b) borbulhamento de ar através do local da ruptura da peça cirúrgica submersa em água.

\section{Da superfície interna da peça cirúrgica e preparo das amostras teciduais}

Procedeu-se a abertura no bordo mesocólico através de secção longitudinal. Observou-se o aspecto da mucosa ao nível da sutura e foi classificada em: deficiente, quando havia solução de continuidade ou deiscência; regular, quando apresentava irregularidade na coaptação dos bordos, sinais hemorrágicos e ou necrose, sem sinais de deiscência; e bom, na presença de continuidade e uniformidade harmônica na integração de seus bordos 9 .

Em seguida retiraram-se dois fragmentos teciduais de cada peça $1,5 \times 1,5 \mathrm{~cm}$ da parede cecal, tendo a sutura no seu ponto médio e identificadas as peças individualmente. $\mathrm{O}$ primeiro fragmento foi colocado em frasco de vidro com solução de formol a $10 \%$ e encaminhado para processamento histológico. O outro fragmento foi colocado em frasco de vidro com solução salina a $0,9 \%$ e congelado a $-20^{\circ} \mathrm{C}$.

\section{Avaliação microscópica}

O material foi submetido a processamento histológico rotineiro, confeccionando-se blocos de parafina. Foi realizada microtomia na espessura de $4 \mu \mathrm{m}$, e os cortes foram corados pela técnica da hematoxilina e eosina. Avaliaram-se, na área de anastomose, os seguintes parâmetros: a) processo inflamatório; b) poliferação fibroblástica; c) colagenização; d) re-epitelização; e) coaptação das bordas da anastomose.

\section{Dosagem da taxa de hidroxiprolina tecidual}

A concentração da taxa foi definida em miligramas de hidroxiprolina por grama de tecido. Utilizou-se a técnica fotocolorimétrica proposta por Kivirikko et al. ${ }^{14}$, modificada por Ibbott $^{10}$.

\section{Análise estatística}

Calcularam-se os valores médios, desvio-padrão, mediana, intervalo de confiança de $95 \%$ bem como valores mínimo e máximo. Determinou-se ainda a comparação dos valores entre os grupos e subgrupos pelo teste paramétrico de Tukey-Kramer para múltiplas comparações (ANOVA). A análise dos dados histológicos foi feita pelo teste exato de Fisher. Os testes estatísticos foram realizados pelo programa GraphPad InStat 3.1 e StatMet (Califórnia, USA).

\section{RESULTADOS}

\section{Avaliação macroscópica}

Exame da parede, cavidade abdominal e da superfície externa da peça cirúrgica

A cicatrização da parede abdominal foi considerada boa em todos os animais, sem sinais clínicos de infecção ou deiscência.

$\mathrm{Na}$ avaliação da cavidade abdominal não se observou sinais clínicos de abscesso localizado ou peritonite. Todos, exceto dois animais $\left(14^{\circ}\right.$ do grupo polipropilene e $3^{\circ}$ poligle- 
caprone), apresentaram aderências na sutura do ceco. Na maioria das vezes, a estrutura envolvida era o omento maior.

Ao avaliar-se a área de sutura, não se observou indícios de abscessos, deiscências ou fístulas em nenhuma das peças estudadas.

\section{Teste de resistência à insuflação de ar atmosférico}

No $3^{\circ}$ dia de pós-operatório, o vazamento de ar ocorreu na linha de sutura em todos os animais. Em quatro animais do $7^{\circ}$ dia dos grupos polipropilene e glicomer, o vazamento ocorreu na linha de sutura e nos outros quatro distante dela; no grupo poliglecaprone, três vazamentos ocorreram na linha de sutura e cinco distantes dela. No $14^{\circ}$ dia de pós-operatório dos grupos poliglecaprone e glicomer, em dois animais o vazamento ocorreu na linha de sutura e em seis distante dela; no grupo polipropilene, um vazamento ocorreu na linha de sutura e sete distante dela. Comparando-se os tempos de avaliação de $3^{\circ}$ e $14^{\circ}$ dias de pós-operatório, encontrou-se no $14^{\circ}$ dia significativamente mais pontos de vazamento de ar longe da anastomose do que no $3^{\circ}$ dia, em todos os grupos estudados (grupo polipropilene: $P=0,0014$; grupo poliglecaprone: $P=0,007$; grupo glicomer: $P=0,007$ ).

Os valores médios de resistência à insuflação de ar observados no grupo polipropilene foram $63,87 \mathrm{mmHg}$, $127,87 \mathrm{mmHg}$ e $172,37 \mathrm{mmHg}$ no $3^{\circ}, 7^{\circ}$ e $14^{\circ}$ dias de pósoperatório respectivamente. No grupo poliglecaprone, os valores médios observados foram $42,87 \mathrm{mmHg}, 168,37$ $\mathrm{mmHg}$ e $144,25 \mathrm{mmHg}$ no $3^{\circ}, 7^{\circ}$ e $14^{\circ}$ dia de pós-operatório respectivamente; e no grupo glicomer os valores médios observados foram 54,25 mmHg, 147,25 $\mathrm{mmHg}$ e 147,87 $\mathrm{mmHg}$ no $3^{\circ}, 7^{\circ}$ e $14^{\circ}$ dia de pós-operatório respectivamente.

$\mathrm{Na}$ análise desses resultados, não se observou diferença significativa nas pressões entre os grupos no período de avaliação do 30 dia; de maneira análoga, também não se observou diferença estatisticamente significante entre os grupos estudados no $7^{\circ}$ e no $14^{\circ}$ dias de pós-operatório. Observou-se aumento estatisticamente significativo da pressão auferida, comparando-se os dias 3 e 7 de pósoperatório, em todos os grupos.

\section{Exame da superfície interna da peça cirúrgica ao nível da sutura}

No $3^{\circ}$ dia de pós-operatório, a superfície interna da peça cirúrgica na sutura foi classificada como "bom" em todas as oito observações do grupo polipropilene, em sete do poliglecaprone e em sete do glicomer, e como "regular" em uma observação dos grupos poliglecaprone e glicomer. No $7^{\circ}$ dia de pós-operatório foi classificada como "bom" em sete observações do grupo polipropilene, em seis do poliglecaprone e em todos os oito do glicomer, e como "regular" em um do grupo polipropilene e dois animais do poliglecaprone. No $14^{\circ}$ dia de pós-operatório classificouse como "bom" em todas as observações dos três grupos estudados.

\section{Avaliação microscópica}

\section{Reação inflamatória aguda}

No $3^{\circ}$ dia de pós-operatório, ela foi classificada como "discreta" em um animal do grupo polipropilene, em dois do poliglecaprone e em nenhum do glicomer; como "moderada" em três animais do grupo polipropilene, em quatro do poliglecaprone e em três animais do glicomer; e como "intensa" em quatro do polipropilene, em dois do poliglecaprone e em cinco do glicomer. Não houve diferença estatisticamente significante entre os grupos.

No $7^{\circ}$ dia, a reação inflamatória aguda foi classificada como "discreta" em quatro animais do grupo polipropilene, em um do poliglecaprone e em dois do glicomer; como "moderada" em quatro animais do grupo polipropilene, em seis do poliglecaprone e em quatro do glicomer; e como "intensa" em nenhum do grupo polipropilene, em um do poliglecaprone e em dois do glicomer. Não houve diferença estatisticamente significante entre os grupos.

No $14^{\circ}$ dia, a reação inflamatória aguda esteve ausente em dois animais do grupo polipropilene; como "discreta" em cinco do polipropilene, em cinco do poliglecaprone e em seis animais do glicomer; como "moderada" em um animal do grupo poliglecaprone, em três do poliglecaprone e em dois do glicomer. Não houve diferença estatisticamente significante entre os grupos.

\section{Reação inflamatória crônica}

No $3^{\circ}$ dia de pós-operatório, a reação inflamatória crônica esteve ausente, apenas, em um animal do grupo polipropilene; como "discreta" em sete do polipropilene, em oito do poliglecaprone e em oito do glicomer. Não houve diferença estatisticamente significante entre os grupos.

No $7^{\circ}$ dia, a reação inflamatória crônica foi observada em todos os animais de todos os grupos. Foi classificada como "discreta" em três animais do grupo polipropilene, em seis do poliglecaprone e em quatro do glicomer; e como "moderada" em cinco animais do grupo polipropilene, em dois do poliglecaprone e em quatro do glicomer. Não houve diferença estatisticamente significante entre os grupos.

No $14^{\circ}$ dia, foi observada reação inflamatória crônica em todos os animais de três grupos. Foi classificada como "discreta" em sete animais do grupo polipropilene, em sete do poliglecaprone e em sete do glicomer; e como "moderada" em um animal do grupo polipropilene, em um do poliglecaprone e em um do glicomer. Não houve diferença estatisticamente significante entre os grupos.

\section{Proliferação fibroblástica}

No $3^{\circ}$ dia de pós-operatório, a proliferação fibroblástica foi classificada como ausente em um animal do grupo polipropilene; como "discreta" em cinco animais do grupo polipropilene, em seis do poliglecaprone e em cinco do glicomer; como "moderada" em dois animais do grupo polipropilene, em dois do poliglecaprone e em três do glicomer. Não houve diferença estatisticamente significante entre os grupos.

No $7^{\circ}$ dia, a proliferação fibroblástica foi classificada como "discreta" em um animal do grupo polipropilene e em 
dois do glicomer; como "moderada" em cinco do polipropilene, em cinco do poliglecaprone e em seis do glicomer; e como "intensa" em dois animais do grupo polipropilene e em três do poliglecaprone. Não houve diferença estatisticamente significante entre os grupos.

No $14^{\circ}$ dia, a proliferação fibroblástica no grupo polipropilene foi "moderada" em sete animais e como "intensa" em um; no grupo poliglecaprone foi classificada como "moderada" em seis animais e "intensa" em dois; e no grupo glicomer como "moderada" em cinco e intensa em três. Não houve diferença estatisticamente significante entre os grupos.

\section{Colagenização}

No $3^{\circ}$ dia de pós-operatório, ela foi classificada no grupo polipropilene como ausente em três animais e como "discreta" em cinco; no grupo poliglecaprone como ausente em dois, como "discreta" em cinco e como "moderada" em um; e no grupo glicomer como ausente em quatro animais e como "discreta" em quatro. Não houve diferença estatisticamente significante entre os grupos.

No $7^{\circ}$ dia, no grupo polipropilene foi classificada como "discreta" em um animal e como "moderada" em sete; no grupo poliglecaprone como "discreta" em seis e "moderada" em dois; e no grupo glicomer como "discreta" em seis e moderada em dois. Houve significativamente mais animais do subgrupo polipropilene com colagenização "moderada" do que nos subgrupos poliglecaprone e glicomer $(P=0,0406)$.

No $14^{\circ}$ dia, ela no grupo polipropilene foi classificada como "moderada" em seis animais e como "intensa" em dois; no grupo poliglecaprone "moderada" em sete e "intensa" em um; e no grupo glicomer como "moderada" em seis e "intensa" em dois. Não houve diferença estatisticamente significante entre os grupos.

\section{Coaptacão das bordas da anastomose}

No $3^{\circ}$ dia de pós-operatório, no grupo polipropilene foi classificada ausente em dois animais e parcial em seis; no poliglecaprone ausente em dois animais e parcial em seis; e no grupo glicomer ausente em três animais e parcial em cinco. Não houve diferença estatisticamente significante entre os grupos.

No $7^{\circ}$ dia, no grupo polipropilene era ausente em um animal, parcial em cinco e completa em dois; no grupo poliglecaprone ausente em um animal e parcial em sete; e no grupo glicomer ausente em um animal, parcial em cinco e completa em dois. Não houve diferença estatisticamente significante entre os grupos.

No $14^{\circ}$ dia, no grupo polipropilene foi classificada como parcial em dois animais e completa em seis; no poliglecaprone como parcial em dois e completa em seis; e no glicomer completa em oito animais. Não houve diferença estatisticamente significante entre os grupos.

\section{Re-epitelização}

No $3^{\circ}$ dia de pós-operatório, no grupo polipropilene estava ausente em quatro animais e presente em quatro, todas de forma parcial; no grupo poliglecaprone estavam ausentes em dois e presentes em seis animais, todas de for- ma parcial; e no grupo glicomer ausente em um e presente em sete, também, de forma parcial. Não houve diferença estatisticamente significante entre os grupos.

No $7^{\circ}$ dia, no grupo polipropilene estava presente em todos os animais, sendo sete de forma parcial e uma completa; no grupo poliglecaprone estava ausente em um animal e presente em sete, todas de forma parcial; e no grupo glicomer estava presente em todos os animais, todas de forma parcial. Não houve diferença estatisticamente significante entre os grupos .

No $14^{\circ}$ dia, estava presente em todos os grupos, sendo que no polipropilene de forma parcial em cinco e completa em três animais; no grupo poliglecaprone de forma parcial em todos os animais; e no grupo glicomer em quatro animais parcial e quatro completa. Não houve diferença estatisticamente significante entre os grupos.

\section{Dosagem da taxa de hidroxiprolina tecidual}

No $3^{\circ}$ dia de pós-operatório, a taxa encontrada foi de $3,280 \mathrm{mg} / \mathrm{g}, 2,7588 \mathrm{mg} / \mathrm{g}$ e $3,740 \mathrm{mg} / \mathrm{g}$ de tecido para os grupos polipropilene, poliglecaprone e glicomer, respectivamente; no $7^{\circ}$ dia, foi de $4,434 \mathrm{mg} / \mathrm{g}, 3,581 \mathrm{mg} / \mathrm{g}$ e $3,969 \mathrm{mg} / \mathrm{g}$ para os mesmos grupos; no $14^{\circ}$ dia de 4,731, 5,338 e 4,858 mg, respectivamente. Na análise estatística não observou-se diferença entre os três grupos (Tabela 1).

TABELA 1 - Taxa de hidroxiprolina tecidual em $\mathrm{mg} / \mathrm{g}$ de tecido \pm desvio-padrão, segundo os grupos e subgrupos

\begin{tabular}{llll}
\hline Grupo & $\mathbf{3}$ dias & $\mathbf{7}$ dias & $\mathbf{1 4}$ dias \\
\hline Polipropilene & $3,280 \pm 2,109$ & $4,434 \pm 1,687$ & $4,731 \pm 2,324$ \\
Poliglecaprone & $2,758 \pm 1,268$ & $3,581 \pm 1,674$ & $5,338 \pm 1,156$ \\
Glicomer & $3,740 \pm 1,409$ & $3,969 \pm 1,761$ & $4,858 \pm 0,562$ \\
\hline
\end{tabular}

\section{DISCUSSÃO}

\section{Avaliação macroscópica}

$\mathrm{Na}$ cavidade abdominal não se constatou presença de abscesso localizado ou peritonite. Estes estudos são semelhantes aos relatados na literatura ${ }^{2}$. Em quase todos os animais foram observadas aderências no nível da anastomose, sendo que na maioria das vezes a estrutura envolvida era omento maior. Tabushi ${ }^{19}$ encontrou aderências em estudo semelhante, realizado para avaliar o fio de poliglecaprone 25 na cecorrafia de ratos, em comparação ao fio de polipropilene.

A classificação do aspecto macroscópico da vista interna, mucosa, das linhas de anastomose, foi semelhante nos grupos e subgrupos entre si. Isso se deve ao fato de a combinação de agulha e fio monofilamentar ser harmônica e adequada, de acordo com as especificações dos fabricantes. As características macroscópicas analisadas a olho nu, refletiram a adequação do material de síntese ao modelo experimental. Porém, não se deve esquecer que, para o cirurgião em campo operatório, resta apenas esse mesmo critério, subjetivo, de controle de qualidade de seu trabalho. Esse, segundo Czeczko ${ }^{4}$, é macroscopicamente elegante, porém microscopicamente traumático. A impressão subjetiva do autor de que o encastoamento do fio de glicomer na agulha, provoca alteração da curvatura da 
parte final dando a sensação de pequeno ponto de resistência à passagem do fio. Este fato não se constituiu em desvantagem.

A avaliação de uma cicatriz tecidual, mediante determinação de resistência mecânica, pode ser realizada por meio de duas técnicas: resistência à insuflação de ar ou água (bursting strength) ou tração linear (breaking strength ou tensile strength $)^{8,11,12}$. Parâmetro de avaliação física de cicatriz tecidual deverá levar em consideração o tipo de forças naturais a que esse tecido está sujeito. Quando o objeto de análise está relacionado a uma víscera oca - como o tubo gastrointestinal -, o teste de resistência à insuflação de ar é fisiológico por reproduzir os vetores de pressão que normalmente se transmitem sobre a parede do intestino, aproximando-se da situação clínica real, visto que o rompimento ocorrerá em função da distensão ${ }^{15}$. Além disso, o teste de resistência à insuflação de ar exerce pressão em toda a circunferência da parede intestinal, submetendo-se à prova de vedação. No entanto, conforme ressalta Ballantyne ${ }^{1}$, esta técnica é útil principalmente nas primeiras duas semanas de pós-operatório, pois após esse período a resistência da anastomse à pressão pode exceder a do tecido intestinal normal, observando-se com frequência escape gasoso distante da anastomose. Esse fenômeno também foi observado no presente estudo. Consequentemente, as medições tardias não refletem exatamente a resistência da anastomose, mas do intestino. Para avaliações da anastomose no período tardio, após o $14^{\circ}$ dia de pós-operatório, pode-se utilizar a determinação da resistência à tração linear de uma tira de tecido isolada.

No presente estudo, observou-se resistência cicatricial à insuflação de ar baixo no $3^{\circ}$ dia de pós-operatório para os três grupos, com elevação no $7^{\circ}$ dia e mantendo-se em níveis semelhantes aos do $7^{\circ}$, no $14^{\circ}$ dia de pós-operatório. Esse resultado confirma a tendência representada pela literatura ${ }^{6,7,11,18}$ e repete o padrão conhecido de baixa resistência à insuflação de ar no período de maior colagenólise, isto é, 3o dia de pós-operatório.

\section{Avaliação histológica}

No presente estudo foram avaliados, comparativamente, os vários parâmetros da reparação tecidual.

No $3^{\circ}$ dia de pós-operatório, observaram-se características semelhantes entre os grupos em relação a todos os parâmetros, que foram predominantemente classificadas de moderadas a intensas na reação inflamatória aguda, de discretas na reação inflamatória crônica e proliferação fibro- blástica, de ausentes ou discretas na colagenização e de ausentes ou parciais na coaptação das bordas e re-epitelização da mucosa. Essas alterações são condizentes desta fase da cicatrização e concernentes ao relatado por Tabushi ${ }^{19}$.

Nas amostras avaliadas no $7^{\circ}$ dia de pós-operatório, registrou-se em todos os grupos tendência para redução da reação inflamatória aguda, apesar de observar-se como intensa em duas observações do grupo glicomer, uma no grupo poliglecaprone e aumento paralelo da proliferação fibroblástica e colagenização, sendo esta significativamente maior no grupo polipropilene. A coaptação das bordas e a re-epitelização das mucosas estavam presentes na maioria das observações, o que também foi descrito por Wendler ${ }^{21}$.

No $14^{\circ}$ dia de pós-operatório, observou-se nos três grupos reação inflamatória discreta e aumento importante da proliferação fibroblástica e colagenização. Tanto a coaptação das bordas como re-epitelização da mucosa estavam presentes em todas as observações de todos os grupos. Esses resultados são semelhantes aos relatados por Hirt?.

\section{Avaliação da taxa de hidroxiprolina tecidual}

A explicação para o fato de que os resultados bioquímicos da dosagem da taxa de hidroxiprolina tecidual no presente estudo não tenham oferecido resultados significantes, pode ser buscada no fato delas serem naturalmente de tamanho diminuto e, ao mesmo tempo, a proporção de tecido correspondente à cicatriz cirúrgica, menor ainda; pode ter ocorrido, assim, efeito de diluição das diferenças. Antevendo essa possibilidade e na tentativa de correção dessa variável, os autores dissecaram e ressecaram cada uma das peças com uso de lupa cirúrgica, limpando-as de tecido gorduroso mesenterial e eventuais aderências locais. Tecidos outros que não a cicatriz e a parede intestinal podem falsificar os resultados, promovendo efeito de diluição pelo aumento do peso da amostra em relação à real taxa de hidroxiprolina encontrada. Estudos semelhantes, realizados em animais de maior porte, em nosso meio, puderam demonstrar estatisticamente a importância da fase de colagenólise sobre a dinâmica colágena da cicatriz ${ }^{4,5,9,21}$.

\section{CONCLUSÃO}

O fio de Monosyn ${ }^{\circledR}$ equiparou-se, nos parâmetros estudados, aos de Prolene ${ }^{\circledR}$ e Monocryl ${ }^{\circledR}$ na realização de sutura em ceco de ratos. 
Nomura LM, Ribas-Filho JM, Malafaia O, Dietz UA, Skare TL, Kume MH. Healing process with polipropilene, poliglecaprone 25 and glicomer 60 in cecorraphy in rats. ABCD Arq Bras Cir Dig 2009;22(2):82-8

ABSTRACT - Background - Surgeons are still looking for the ideal suture material, although the progress during the last decades. Aim - To compare cecorrhaphy in rats with three different sutures: polypropylene (Prolene $\left.{ }^{\circledR}\right)$, polyglecaprone 25 (Monocryl $\left.{ }^{\circledR}\right)$ and glycomer 60 (Monosyn $\left.{ }^{\circledR}\right)$. Method -: Seventy-two Wistar rats were divided into three groups of 24 each (polypropylene, polyglecaprone and glycomer groups). Within each group, the animals were assigned to three subgroups and assessed on the $3 \mathrm{rd}$, 7th and 14th postoperative day. The parameters studied were the bursting strength, macroscopic mucosal healing, histology and tissue hydroxyproline rate. Results - The bursting strength had its lower values on the 3rd postoperative day, with significant higher values on the 7th and 14th; there was no difference among groups. In the overall, the histological analysis of the inflammatory reaction, fibroblast proliferation, collagen formation, border attachment and re-epithelization showed the same pattern among the three groups and sub-groups; only on day 7, there was seen a significant higher collagen formation in polypropylene group than polyglecaprone and glycomer groups. The tissue hydroxyproline rate was significant lower in the sub-groups of the 3rd postoperative day, in all of the three studies groups, with increase on days 7 and 14. There was a parallel gain in bursting strength and neo-collagen formation. Conclusion - There was no difference among glycomer 60 , polypropylene and polyglecaprone sutures in performing cecorrhaphy in rats between days 3 and 14, according to the evaluated parameters.

HEADINGS - Surgical sutures. Cicatrization. Surgery

\section{REFERÊNCIAS}

1. Ballantyne GH. Intestinal suturing. Review of the experimental foundations for traditional doctrines. Dis Colon Rectum. 1983 Dec;26(12):836-43.

2. Bonoldi AP, Cabano F, Bonacina R, Di Giacomo A, Zonta A. Experimental study of colonic anastomoses. Comparison of different suture methods in the rat Minerva Chir. 1989 Apr 15;44(7):1071-4.

3. Braghetto IM, Rappoport JS. Evaluación prospectiva de sutura poliglecaprone

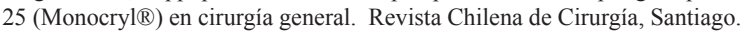
1994;46:299-305.

4. Czeczko NG. Estudo comparativo entre as anastomoses colorretais mecânicas com grampeador e com anel biofragmentável no reto extraperitoneal de cães. Curitiba, 1992. Tese (Doutorado em Clínica Cirúrgica) - Setor de Ciências da Saúde, Universidade Federal do Paraná.

5. Dietz UA, Torres OJM, Insfrán GM, Nassif PAN, Hirt ALA, Repka JCD, Malafaia O, Czeczko NG. Estudo da taxa de hidroxiprolina tecidual nos diversos segmentos do canal alimentar do cão pela técnica fotocolorimétrica utilizando o reativo de Ehrlich. Acta Cir. Bras. 1995;10:128-34.

6. Foresman PA, Edlich RF, Rodeheaver GT. The effect of new monofilament absorbable sutures on the healing of musculoaponeurotic incisions, gastrotomies, and colonic anastomoses. Arch Surg. 1989 Jun;124(6):708-10.

7. Hendriks T, Mastboom WJ. Healing of experimental intestinal anastomoses. Parameters for repair. Dis Colon Rectum. 1990 Oct;33(10):891-901.

8. Herrmann JB, Woodward SC, Pulaski EJ. Healing of colonic anastomoses in the rat. Surg Gynecol Obstet. 1964 Aug;119:269-75.

9. Hirt ALA. Anastomose gastroduodenal realizado com anel biofragmentável cruzando uma linha de grampos versus sutura manual: Estudo experimental em cães. Curitiba, 1997. 98p. Tese (Mestrado em Clínica Cirúrgica), Faculdade Evangélica de Medicina do Paraná.

10. Ibbott FA. Amino acids and related substances. In: chemistry principles and technics. 2. ed. New York, Harper \& Row Publishers, 1974. p.608-614.
11. Jiborn $\mathrm{H}$, Ahonen J, Zederfeldt B. Healing of experimental colonic anastomoses. I. Bursting strength of the colon after left colon resection and anastomosis. Am J Surg. 1978 Nov;136(5):587-94.

12. Jiborn $\mathrm{H}$, Ahonen J, Zederfeldt B. Healing of experimental colonic anastomoses. II. Breaking strength of the colon after left colon resection and anastomosis. Am J Surg. 1978 Nov;136(5):595-9.

13. Katz AR, Turner RJ. Evaluation of tensile and absorption properties of polyglycolic acid sutures. Surg Gynecol Obstet. 1970 Oct;131(4):701-16.

14. Kivirikko KI, Laitinen O, Prockop DJ. Modifications of a specific assay for hydroxyproline in urine. Anal Biochem. 1967 May;19(2):249-55.

15. Koruda MJ, Rolandelli RH. Current research review: experimental studies on the healing of colonic anastomoses. J Surg Res. 1990; 48:504-15.

16. LaBagnara $J \mathrm{~J}$. A review of absorbable suture materials in head \& neck surgery and introduction of monocryl: a new absorbable suture. Ear Nose Throat J. 1995 Jun;74(6):409-15.

17. Miller JM. Evaluation of a new surgical suture (prolene). Am Surg. 1973 Jan;39(1):31-9.

18. Rey SD, Czeczko NG, Nassif PAN, Ribas-Filho JM, Malafaia O, Grisa L, Torres OJM, Czeczko AEA. Perose drain influence in cecum healing. Experimental study in rats. ABCD Arq Bras Cir Dig 17(1):

19. Tabushi FI. Cecorrafia em plano único com polipropilene e com poliglecaprone 25: estudo comparativo em ratos. Curitiba, 1998. 55p. Tese (Mestrado em Clínica Cirúrgica), Faculdade Evangélica de Medicina do Paraná.

20. Warde PJ. Anastomose colorretal experimental em um e em dois planos de sutura: estudo comparativo. São Paulo, 1972. Tese (Doutorado), Faculdade de Medicina da Universidade de São Paulo.

21. Wendler LE. Estudo experimental comparativo da cicatrização de suturas jejunoileais em cães, utilizando o fio de poliglecaprone 25. Curitiba, 1995. 78p. Tese (Doutorado em Princípios da Cirurgia), Faculdade Evangélica de Medicina do Paraná.

Fonte de financiamento: não há

Conflito de interesse: não há

Recebido para publicação: 26/01/2009

Aceito para publicação: 07/03/2009 